American Journal of Pharmaceutical Education 2019; 83 (6) Article 6800.

\title{
RESEARCH
}

\section{Pharmacy Students' Utilization of an Online Tool for Immediate Formative Feedback on Reflective Writing Tasks}

\author{
Cherie Lucas, PhD, ${ }^{\mathrm{a}}$ Andrew Gibson, $\mathrm{PhD},{ }^{\mathrm{b}}$ Simon Buckingham Shum, $\mathrm{PhD}^{\mathrm{b}}$ \\ ${ }^{a}$ University of Technology Sydney, Graduate School of Health-Pharmacy, Sydney, Australia \\ ${ }^{\mathrm{b}}$ University of Technology Sydney, Connected Intelligence Centre, Sydney, Australia \\ Submitted September 19, 2017; accepted April 10, 2018; published August 2019.
}

\begin{abstract}
Objective. To assess pharmacy students' perceptions of the benefits and utility of a novel online reflective-writing tool.

Methods. After completing a required Academic Writing Analytics (AWA) workshop, Master of Pharmacy students submitted a reflective writing assignment in the AWA web application. A six-item survey was administered to students prior to and immediately after using AWA.

Results. Sixty students volunteered to participate in the study; however, only 39 students provided a pseudonym that allowed their pretest and posttest to be matched. A comparison of students' responses on the pretest with those on the posttest, which was administered four weeks after the workshop, suggest a noticeable increase in agreement with AWA's benefits as an effective, online tool for improving their reflective learning skills.

Conclusion. This novel online tool has the potential to assist pharmacy students with self-critiquing and improving their reflective writing assignments prior to submission. Furthermore, as the elements of reflection are transferable, this tool has the potential to be used in other educational contexts.
\end{abstract}

Keywords: reflective practice, evaluation, assessment, reflection, pharmacy education

\section{INTRODUCTION}

Pharmacy educators acknowledge that reflectivelearning processes are not inherent or intuitive skills. Instead, they are skills that are only acquired through education and practice. ${ }^{1-4}$ Developing reflective skills assists pharmacy students to perform better academically ${ }^{5,6}$ and make better clinical decisions, ${ }^{5,7-9}$ Additionally it may enhance self-directed learning. ${ }^{10}$ These skills are also essential for pharmacists to be able to self-critique particularly in professional practice. ${ }^{1,12}$ Furthermore, the importance of reflective skills is not restricted to the pharmacy profession. They are equally important in other health settings, including nursing, medicine, physical therapy, and other allied health specialties. ${ }^{9,13-21}$

Reflective writing is not an easy skill to develop and differs greatly from other forms of writing. ${ }^{1}$ Studies have shown that students perceive reflection and reflective writing as a challenging and confronting task, particularly as it involves an introspective aspect and has personal elements. ${ }^{11,22}$ Despite this, mastering the art of reflection

Corresponding Author: Cherie Lucas, Graduate School of Health-Pharmacy, 67 Thomas St., Ultimo, Bldg. 7, Lvl. 4, Rm. 48, University of Technology Sydney, Sydney, NSW 2007, Australia. Tel: +61-2-9514-4275. E-mail: cherie.lucas@uts.edu.au. is considered essential to the professional development of the pharmacy practitioner. ${ }^{23,24}$ Through reflective writing processes, many health professions schools are assisting students with learning how to critique their own practice skills in order to improve their future practice. ${ }^{16,19,25,26}$ However, the assessment of student performance on reflective tasks requires careful consideration and a clear understanding of the purpose and aim of these exercises. ${ }^{11,27}$ If one of the primary aims of reflection is for students to be able to self-critique their professional practice skills, then an online tool that promotes this process, provides timely feedback, and can be used at any time may be beneficial.

Students' reflective writing can be stimulated by formative feedback provided by their educators. ${ }^{28}$ The sooner students receive feedback after submitting an assessment, the greater the effect the feedback has on their future learning. ${ }^{29,30}$ However, with increasing numbers of students enrolled in higher education and increasing time constraints for academics as they balance teaching and research responsibilities, providing individual formative feedback to each student regularly or in a timely manner is often not possible. ${ }^{31}$ This poses problems for students who require more assistance with a task, particularly one as challenging and confronting as reflective writing. 


\section{American Journal of Pharmaceutical Education 2019; 83 (6) Article 6800.}

There is a growing interest in integrating reflectiveskill development within health education contexts. Furthermore, self-directed learning is an important skill for graduate students as well as health professionals. This, coupled with faculty members' time constraints to provide students with consistent formative feedback was a catalyst for the development and launch of a novel online tool in the pharmacy curriculum. ${ }^{32}$

Academic Writing Analytics (AWA) is a web application designed to provide immediate formative feedback to students on first drafts of their reflective-writing assignments. The app was developed by the Connected Intelligence Centre (CIC), University of Technology Sydney, in collaboration with Xerox Research Centre Europe (XRCE) and academics from diverse disciplines at the University of Technology Sydney (pharmacy, business, ecology, law, and engineering).

Academic Writing Analytics utilizes a range of natural language processing (NLP) techniques to analyze student writing. Natural language processing involves the use of computer algorithms to identify and extract specific features from human language text. These include syntactic features that describe the structure of the text and lexical features based on the words that are used, as well as features intended to capture semantic information. These features are used to identify high-level concepts, which in turn can be used as a basis for providing feedback to the student.

A prototype of AWA was evaluated for its precision and accuracy. The results of that evaluation in which computer output was compared with human annotations was encouraging. ${ }^{31}$ In particular, a second iteration showed promise comparing the parser output (analysis of syntactic features, computer language) with the human annotators of reflective statements among a group of students. Three hundred twelve reflective writing pieces (containing 2366 sentences) from Georgetown University (GU) were analyzed and coded. Coding elements used Carol Rodgers' reflective model drawn from the work of Dewey and colleagues ${ }^{33}$ to distinguish between shallow and deep reflection. Coding consisted of a review of assessment rubrics and independent coding by academics and linguistic graduate students, with a follow-up discussion and shared agreement. Using well-established metrics in classification methodology for precision, recall, accuracy analysis of the comparison between parser output and human annotations showed that accuracy did not decrease significantly with the second iteration compared to the first iteration. This showed promise with regards to reliability of the tool as the first iteration only analyzed 30 reflective pieces containing 382 sentences while the second iteration analyzed approximately 10 times as many reflective pieces as the first. ${ }^{31}$

This study aimed to identify pharmacy students' perceptions of the benefits and utility of using a novel, online tool to provide formative feedback to them prior to submitting their reflective writing tasks for summative assessment.

\section{METHODS}

The AWA tool provides students constructive, formative feedback on drafts of reflective writing. ${ }^{32}$ This feedback is provided on screen in the form of tags (color-coded symbols) and bold type to indicate reflective writing elements. The AWA is not used for summative purposes and hence does not provide a score of student performance. ${ }^{31}$ As no grade is given, the user's focus is directed toward learning with regards to the writing task and incorporating reflective elements into their writing. As AWA's output was drawn from the literature and grading rubrics grounded in the reflection process, AWA's output uses terminology aligned with the summative reflective rubric. Students can access the tool at any time, which may be particularly useful for when they are on experiential placement and require timely feedback, or in rural or remote areas where faculty members may not be available to provide feedback. Using AWA requires students to enter their reflective text into a text box in the web interface or upload a file. The student submits the text and within seconds a reflection feedback report is provided. The AWA web application sends the text to a text analytics pipeline (TAP) to be analyzed using the aforementioned NLP, resulting in analytics based on the input text. The resulting analytics are rendered by the web application in the form of a feedback report for the students to review. An example of the feedback AWA provided on an actual pharmacy student's reflective statement is provided in Appendix 1. Primarily, feedback is provided through annotations in the text in the form of visual tags. This is accompanied by some textual feedback underpinned by the literature, ie, theories about the reflective process and drawn from grading rubrics ${ }^{31,32}$ prompting the writer to self-critique their reflective writing. Three primary tags (color-coded symbols) were developed based on the theoretical conceptions of reflection, reflexivity, and reflective writing: a blue square tag (context) indicates reflection on initial thoughts and feelings about a significant event, situation, or experience; a pink circle tag (challenge) represents challenges within the reflective process, and a green triangle tag (change) represents a higher-order thinking process that indicates students have made a shift in 


\section{American Journal of Pharmaceutical Education 2019; 83 (6) Article 6800.}

perspective that will lead to change in behavior, attitude, or approach to future learning. As the Journal only publishes figures in black and white, the original tags are described in the example provided only in terms of shape (Appendix 1). A color version of Appendix 1 can be found at http://bit.ly/Lucas_AJPE_Apndx1, https://www.youtube. $\mathrm{com} /$ watch?time_continue $=162 \mathrm{\& v}=\mathrm{N} 8 \mathrm{O} 6 \mathrm{aIpB} 2 \mathrm{f} 8$, and https://www.youtube.com/watch?v=vl9fpKtbLfY\&feature $=$ youtu.be.

In addition to the tags, short groups of words or expressions are emphasized with plain lines indicating a belief, learning, or knowledge; dotted lines indicating self-critique; and dashed lines indicating strong feelings. Bolded words indicate deeper reflection, with one or more of the tagged sentences showing evidence of personal application. The colored symbols allow the student to instantly recognize the key elements of the reflective process, and a "guidance tab" (not shown in Appendix 1), which they can refer to at any stage, automatically protrudes onto the interface, prompting and providing students with the meanings for all tags and indicators. The AWA tool can be used multiple times as students revise their work prior to submission for final assessment. ${ }^{32}$

The study was approved by the Research Ethics Committee of the University of Technology Sydney. Clinical Practice for Pharmacy is a required six-credit unit of study offered to first-year Master of Pharmacy (MPharm) students at the Graduate School of Health-Pharmacy, University of Technology Sydney. This unit of study focuses on developing reflective practice skills in the clinical environment (experiential placements), and students are required to maintain an ePortfolio and write about their weekly clinical experiences using reflective writing processes. The reflective statements are documented in the e-portfolio and graded midsemester and again at the end of the semester. The reflective statements are graded using a reflective rubric adapted from the previous work of Tsingos and colleagues (Table 1), ${ }^{11}$ which was drawn primarily from Boud's Stages of reflection ${ }^{34}$ and Mezirow's categories of reflection, ${ }^{35}$ including elements that use a rubric by Wetmore and colleagues. ${ }^{36}$

Students (20 years and older; $N=67$ ) who were enrolled in the unit of study were invited to participate in the study. A participant information statement (PIS) was provided for students to sign prior to the study indicating that if they chose to participate, it would not affect their grades. To maintain confidentiality, the PIS also indicated the students were to provide a pseudonym on the pretest and posttest, which would allow researchers to match data without identifying any students or their responses.

Prior to administering the survey, the course coordinator delivered a required, one-hour workshop to demonstrate use of AWA. Students were then provided with a link to an online, anonymous survey (pretest) where they were asked to provide a pseudonym that would be retained for use on the posttest. The online survey consisted of six quantitative items rated on a 6-point Likert-type scale ranging from $1=$ strongly disagree to $6=$ strongly agree. Students were asked to indicate to what extent they were in agreement with the statements related to the AWA tool (Table 2). After completing the pretest, students were instructed to use AWA to write and revise their weekly reflections for four weeks, and then complete the posttest.

Data from the completed questionnaires were collated and analyzed by a research fellow working in an area external to the pharmacy discipline. Data collected from question 3 was flipped during analysis to represent the positive orientation of this negative question, ie, AWA "is unlikely to be a useful tool for pharmacy education."

\section{RESULTS}

Of the 67 final-year MPharm students, 60 volunteered to participate in the study, for a response rate of $90 \%$. Because not all of the students created a pseudonym, which was required to match the pre- and posttest data, only 39 pre- and posttest survey instruments could be matched and analyzed. The average student agreement to questions 1 through 6 and standard deviations for each question on the pretest and for the posttest are presented in Table 2. There was a significant increase from pretest to posttest in students' agreement with the following AWA benefits: assists with self-directed learning ( $p=.053)$, is relevant to pharmacy professional practice $(p=.024)$, and enhances student confidence in their ability with writing their submissions $(p=.05)$. Students' responses to question 3 were also statistically significant $(p=.016)$ (Table 2 ) indicating AWA as a useful educational tool.

\section{DISCUSSION}

This study aimed to identify pharmacy students' perceptions of the benefits and utility of an online, formative feedback tool. The study findings support previous research and suggest that the AWA tool has the potential to assist students with developing their reflective writing skills by providing formative feedback to them in a timely fashion. ${ }^{32}$ The strengths of this study include that students volunteered for the study and used the tool in their own time. Also, because the students were asked to provide a pseudonym to de-identify themselves, the data collected were likely honest responses. In addition to the fair response rate, a noticeable increase in students' agreement 
American Journal of Pharmaceutical Education 2019; 83 (6) Article 6800.

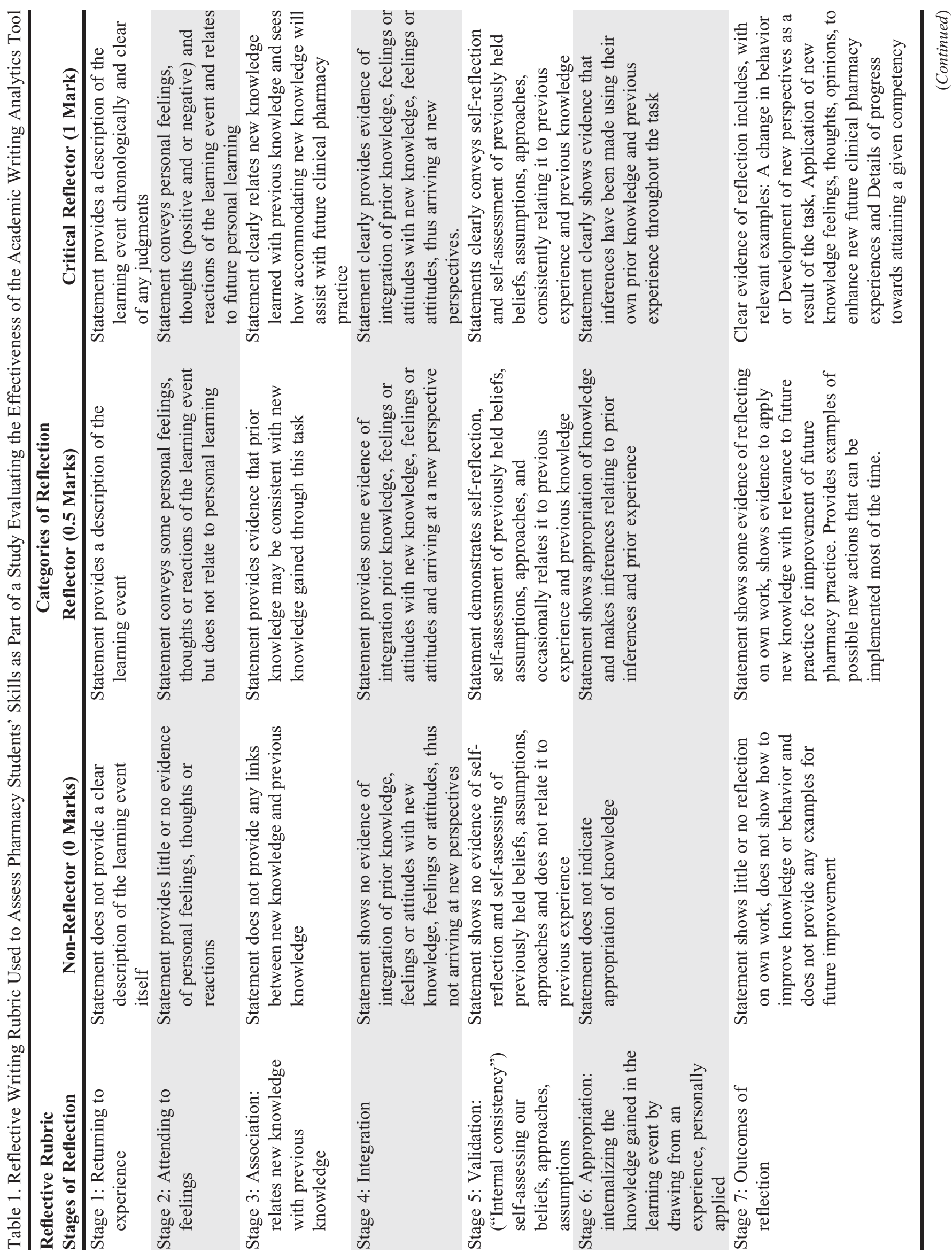


American Journal of Pharmaceutical Education 2019; 83 (6) Article 6800.

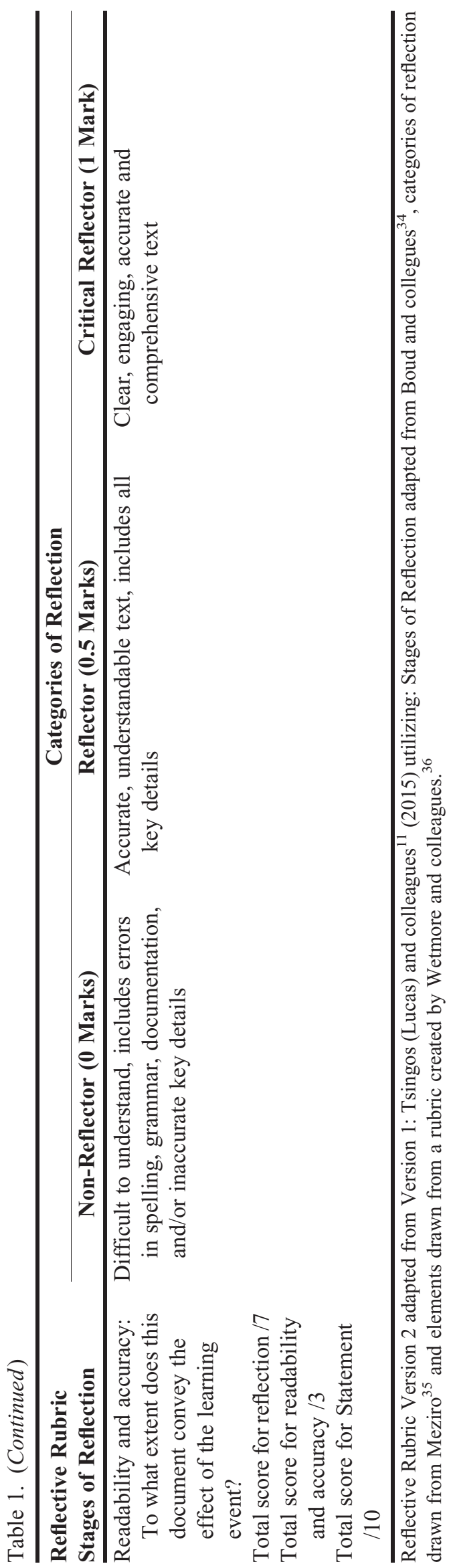

with survey items regarding AWA's benefits after using the tool for four weeks suggest they were engaged in the task. The pharmacy students in this study perceived that the greatest benefits of the AWA tool related to its usefulness for pharmacy education (question 3); its potential to enhance students' self-directed learning skills (question 4); its relevance to the pharmacy profession (question 5 ); and its capacity to increase students' confidence in writing reflective statements (question 6). Although most pharmacy students agreed that the AWA tool assisted their development of reflective writing skills (question 1) and ability to critique their own work (question 2), these benefits were considered secondary compared to the benefits related to questions 3, 4, 5, and 6. Perhaps this was because students perceived AWA more as a useful, educational tool for their self-directed learning and feedback rather than one that developed their skills in critiquing their reflective writing.

The study findings may not be generalizable to all pharmacy students, thus presenting a potential limitation. Further studies investigating AWA's use with students' reflective-writing tasks at other pharmacy schools would be beneficial. A limitation of this study was that only students' perception of the tool's benefits and utility were reported while students' performance was not measured. There are limitations to using artificial intelligence programs such as AWA; hence, students must develop a critical mindset when using such a tool. For example, students should be allowed to question AWA's critiques of their writing, which is a positive effect of using such a tool. The AWA web application does not provide students with a performance score/grade; therefore, students and educators may find it difficult to track improvements in performance. Despite this limitation, the majority of students engaged with the task voluntarily and perceived value in the feedback that AWA provided. Enhanced performance may be measured in future studies via the collection of analytical data related to changes in students' reflection writing (ie, comparing the first task submitted with the final task submitted) after self-critiquing with the assistance of AWA. Analytical data collection could include changes (increases) in the number of tags/symbols (indicating the various elements of the reflection process) and the "boldness" of the writing (indicating deeper reflection, personally applied). Future research could include investigating whether a relationship exists between students who score higher grades as assessed using the reflective writing rubric and their use of AWA. Qualitative analysis of students' initial reflections and comparison with their final reflections prior to summative assessment could also be beneficial in tracking their performance. 


\section{American Journal of Pharmaceutical Education 2019; 83 (6) Article 6800.}

Table 2. Students' Perceptions of Using the Academic Writing Analytics Tool to Assess Their Reflective Writing Skills

\begin{tabular}{|c|c|c|c|c|}
\hline \multicolumn{2}{|c|}{$\begin{array}{l}\text { Likert Scale-type Questions* } \\
\text { N=39 }\end{array}$} & \multirow{2}{*}{$\begin{array}{c}\begin{array}{c}\text { Pretest Average Student } \\
\text { Response M (SD) }\end{array} \\
3.4(0.9)\end{array}$} & \multirow{2}{*}{$\begin{array}{c}\begin{array}{c}\text { Posttest Average Student } \\
\text { Response, M (SD) }\end{array} \\
3.4(0.6)\end{array}$} & \multirow{2}{*}{$\begin{array}{c}p \\
\text { Value }\end{array}$} \\
\hline Q1 & $\begin{array}{l}\text { Utilizing the AWA online reflective tool assists with the } \\
\text { development of my reflective writing skills }\end{array}$ & & & \\
\hline Q2 & $\begin{array}{l}\text { Utilizing the AWA online reflective tool assists with } \\
\text { critiquing my own work }\end{array}$ & $3.3(1.1)$ & $3.3(0.6)$ & 1.0 \\
\hline Q3 & $\begin{array}{l}\text { Utilizing the AWA online reflective tool is unlikely } \\
\text { to be a useful tool for pharmacy education }\end{array}$ & $1.6(1.0)$ & $2.3(1.5)$ & .016 \\
\hline Q4 & $\begin{array}{l}\text { Utilizing the AWA online reflective tool enhances my } \\
\text { self-directed learning skills }\end{array}$ & $2.8(1.4)$ & $3.4(1.0)$ & .053 \\
\hline Q5 & $\begin{array}{l}\text { Utilizing the AWA online reflective tool is relevant to } \\
\text { pharmacy professional practice }\end{array}$ & $2.8(1.4)$ & $3.4(1.0)$ & .024 \\
\hline Q6 & $\begin{array}{l}\text { Utilizing the AWA online reflective tool makes students } \\
\text { more confident with writing submissions }\end{array}$ & $3.2(1.1)$ & $3.7(1.0)$ & .050 \\
\hline
\end{tabular}

${ }^{a}$ Data was flipped during analysis to represent the positive orientation of this negatively phrased question

\section{CONCLUSION}

The findings of this study suggest that the novel online reflective learning tool, AWA, has the potential to assist pharmacy students to become more confident with their reflective writing tasks. As reflective writing skills have gained traction within educational contexts, future studies including the use of the AWA tool in other health education or broader educational contexts may be beneficial.

\section{ACKNOWLEDGMENTS}

The authors acknowledge the students in the Master of Pharmacy degree in the Graduate School of Health at the University of Technology Sydney who volunteered to participate in this study. Also, the authors acknowledge pharmacy student Matthew Kabalan for allowing us to use his reflective statement in this publication. The authors also acknowledge the significant contribution made by Adam Aitken and Ágnes Sandor in the development of the reflective writing analytics implemented in AWA.

\section{REFERENCES}

1. Brockbank A, McGill I. Facilitating Reflective Learning in Higher Education. 2nd ed. Berkshire, England: Society for Research into Higher Education and Open University Press; 2007.

2. Tsingos C, Bosnic-Anticevich S, Smith L. Learning styles and approaches: can reflective strategies encourage deep learning? Curr Pharm Teach Learn. 2015;7:492-504.

3. Russell T. Can reflective practice be taught? Reflective Practice. 2005;6:199-204.

4. Karkabi K, Wald HS, Castel OC. The use of abstract paintings and narratives to foster reflective capacity in medical educators: a multinational faculty development workshop. Med Humanities. 2014; 40:44-48.

5. Tsingos-Lucas C, Bosnic-Anticevich S, Schneider CR, Smith L. Using reflective writing as a predictor of academic success in different assessment formats. Am J Pharm Educ. 2017;81(1):Article 8.
6. Tsingos C, Bosnic-Anticevich S, Smith L. Does a learning style preference for processing information through reflection impact the academic performance of a cohort of undergraduate pharmacy students? Pharm Educ. 2015;15(1):241-248.

7. Cutrer WB, Sullivan WM, Fleming AE. Educational strategies for improving clinical reasoning. Curr Probl Pediatr Adolesc Health Care. 2013;43:248-257.

8. Mamede S, Schmidt HG, Penaforte JC. Effects of reflective practice on the accuracy of medical diagnoses. Med Educ. 2008;42:468-475.

9. Croke E. The use of structured reflective journal questions to promote fundamental development of clinical decision-making abilities of the first semester nursing student. Contemp Nurse. 2004; $17: 125-136$.

10. Tsingos C, Bosnic-Anticevich S, Smith L. Reflective practice and its implications for pharmacy education. Am J Pharm Educ. 2014;78(1):Article 18.

11. Tsingos C, Bosnic-Anticevich S, Lonie J, Smith L. A model for assessing reflective practices in pharmacy education. Am J Pharm Educ. 2015;79(8):Article 124.

12. Wallman A, Lindblad AK, Hall S, Lundmark A, Ring L. A categorization scheme for assessing pharmacy students' levels of reflection during internships. Am J Pharm Educ. 2008;72(1):

Article 5.

13. Plack MM, Greenberg L. The reflective practitioner: reaching for excellence in practice. Pediatrics. 2005;116:1546-1552.

14. Bulman C, Lathlean J, Gobbi M. The concept of reflection in nursing: qualitative findings on student and teacher perspectives. Nurse Educ Today. 2012;32:e8-e13.

15. Donaghy M, Morss K. An evaluation of a framework for facilitating and assessing physiotherapy students' reflection on practice. Physiother Theory Pract. 2007;23:83-94.

16. Constantinou M, Kuys SS. Physiotherapy students find guided journals useful to develop reflective thinking and practice during their first clinical placement: a qualitative study. Physiother (United Kingdom). 2013;99:49-55.

17. Lachman N, Pawlina W. Integrating professionalism in early medical education: The theory and application of reflective practice in the anatomy curriculum. Clin Anat. (Med Educ). 2006;19:456-460. 18. Brigley S. Continuing education for medical professionals: a reflective model. Postgrad Med J. 1997;73:23-26. 


\section{American Journal of Pharmaceutical Education 2019; 83 (6) Article 6800.}

19. Rees KL. The role of reflective practices in enabling final year nursing students to respond to the distressing emotional challenges of nursing work. Nurs Educ Pract. 2013;13:48-52.

20. Butani L, Blankenburg R, Long M. Stimulating reflective practice among your learners. Pediatrics. 2013;131:204-206.

21. Moon J. Reflective Journals: A Handbook for Reflective Practice and Professional Development. 2nd ed. London: Routledge Falmer; 2006.

22. Tsingos-Lucas C, Bosnic-Anticevich S, Smith L. A retrospective study on students' and teachers' perceptions of the reflective ability clinical assessment. Am J Pharm Educ. 2016;80(6): Article 101.

23. Schön DA. Educating the reflective practitioner: Jossey-Bass San Francisco; 1987.

24. Plack MM, Driscoll M, Blissett S, McKenna R, Plack TP. A method for assessing reflective journal writing. $J$ Allied Health. 2005;34:199-208.

25. Ramli A, Ruslan AS, Sukiman NS. Reflection of physiotherapy students in clinical placement: a qualitative study. Sains Malaysiana. 2012;41:787-793.

26. Wald HS, Reis SP. Beyond the margins: reflective writing and development of reflective capacity in medical education. $J$ Gen Intern Med. 2010;25:746-749.

27. Richardson G, Maltby H. Reflection-on-practice: enhancing student learning. J Adv Nurs. 1995;22:235-242.

28. Poldner E, Van der Schaaf M, Simons PR-J, Van Tartwijk J, Wijngaards G. Assessing student teachers' reflective writing through quantitative content analysis. European Journal of Teacher Education. 2014;37:348-373.

29. Irons A. Enhancing Learning Through Formative Assessment and Feedback. Abingdon, UK: Routledge; 2008.

30. Biggs J, Tang C. Teaching for Quality Learning at University. 4th Edition ed. Berkshire, England: Open University Press; 2011. 31. Buckingham Shum S, Goldsmith R, Bass R, McWilliams M. Towards reflective writing analytics: rationale, methodology and preliminary results. $J$ of Learning Analytics 2017;4(1):58-84. http://www.learning-analytics.info/journals/index.php/JLA/article/ view/5136. Accessed February 15, 2018 doi: http://dx.doi.org/ 10.18608/jla.2017.41.5.

32. Gibson A, Aitken A, Sandor A, Buckingham Shum S, Tsingos-Lucas C, Knight S. Reflective writing analytics for actionable feedback. Proceedings of LAK17: 7th International Conference on Learning Analytics and Knowledge, March 13-17, 2017, Vancover, Canada.

33. Rodgers C. Voices inside schools. Harvard Educ Rev. 2002;72:230-254.

34. Boud D, Keogh R, Walker D. Promoting Reflection in Learning: A Model. Reflection: Turning Experience into Learning. London, Kogan Page; New York, Nicols Pub1985:18-40.

35. Mezirow J. Transformative Dimensions of Adult Learning. San Francisco: Jossey-Bass; 1991.

36. Wetmore AOK, Boyd LD, Bowen DM, Pattillo RE. Reflective blogs in clinical education to promote critical thinking in dental hygiene students. J Dent Educ. 2010;74:1337-1350. 


\section{American Journal of Pharmaceutical Education 2019; 83 (6) Article 6800.}

Appendix 1. Example of a Feedback from AWA on a Pharmacy Student's Reflective Statement

\begin{tabular}{|c|c|c|c|c|c|c|c|}
\hline UTS:U்CIC & xerox & ₹ Home & Reflection & כ Reports & (2) About & $\approx$ Contact & 2 Andrew \\
\hline & AWA Feedback & $\equiv \operatorname{TAP}$ & & & & (1) Guide & Tour \\
\hline
\end{tabular}

encounter. I initially felt quite sorry and concerned for the mother of the patient. I also recall thinking that this was an unfair decision made by the pharmacist as the mother had a right to know as this was her son. I had never previously given thought to this idea, as I thought a patient's medications and medical conditions are fine to discuss with other family members. These feelings really challenged my beliefs and made me think deeply about whether or not my initial views were correct. I previously held a view that patients would want to let their family members know about their condition. I had probably developed this view as my mother suffers from chronic pain, and she personally doesn't have any problem with her family members knowing. What I had learnt from this experience is that each patient has a set of rights, including the right to keep their clinical picture private. On a more fundamental level, when I compared my previous set of knowledge with the new knowledge obtained, I had come to a realisation that each patient is unique and has their own personal thoughts and opinions. If I didn't experience this event, I may not have considered confidentiality on an individual level, and thus could have easily breached someone's privacy. Thus, this could have potentially lead to ethical misconduct and inappropriate practice as a pharmacist. This experience has taught me to always ensure that I practice ethically and not make any assumptions about patients. It also has motivated me to protect the patient's privacy and respect their rights. $\triangle$ I should never discuss a patient's certain clinical picture with anyone besides the patient themselves and other health care professionals who are also treating the patient. This relates to Domain 1: Professionalism and Ethics, Standard 2: Observe and Promote Ethical Standards, which is a standard in the National Competency Standards Framework for Pharmacists in Australia (2016). $\triangle$ I should always maintain a high degree of privacy with patients as this is a fundamental right that they have. Failing to do so is an ultimate breach of their confidentiality, and thus holds a pharmacist accountable for improper practice. 